$1-1-2004$

\title{
Comparisons Compared: A Methodological Survey of Comparisons of Religion from 'A Magic Dwells' to A Magic Still Dwells
}

David M. Freidenreich

Colby College, dfreiden@colby.edu

Follow this and additional works at: https://digitalcommons.colby.edu/faculty_scholarship

Part of the Religion Commons

\section{Recommended Citation}

Freidenreich, David M., "Comparisons Compared: A Methodological Survey of Comparisons of Religion from 'A Magic Dwells' to A Magic Still Dwells" (2004). Faculty Scholarship. 21.

https://digitalcommons.colby.edu/faculty_scholarship/21

This Article is brought to you for free and open access by Digital Commons @ Colby. It has been accepted for inclusion in Faculty Scholarship by an authorized administrator of Digital Commons @ Colby. 


\title{
COMPARISONS COMPARED: \\ A METHODOLOGICAL SURVEY \\ OF COMPARISONS OF RELIGION
}

FROM "A MAGIC DWELLS" TO A MAGIC STILL DWELLS

\author{
DAvid M. Freidenreich
}

\section{Comparison and its critics}

The project of comparative religion, a mainstay of the academic study of religion from the time of its inception, has justifiably drawn sharp criticism from postmodernist circles for its association with the colonial and Orientalist enterprises of Western scholarship. Critics have asserted that the comparison of religion is inherently flawed because of its emphasis on similarity and minimization of differences between religious traditions, as well as its failure to consider religious phenomena in their original contexts. Critics also point out the biases which scholars inevitably bring to their comparisons. For these reasons, many have called for an end to such comparative endeavors. Yet Jonathan Z. Smith, whose article, "In comparison a magic dwells", was among the most influential of these postmodernist critiques, concludes his work with a dramatic insistence on the need for viable, methodologically defensible comparisons of religion (1982a: 35). Since that time, scholars have continued to compare phenomena in multiple religious traditions and have engaged critiques of this practice both by incorporating many postmodernist principles into their comparative methodologies and by offering counter-arguments regarding the importance of properly-constructed comparisons in the study of religion. A collection of essays reflecting on these responses to the postmodernist critique in general and to Smith's article in particular was published as A Magic Still Dwells (Patton and Ray 2000). These two works constitute important milestones in the methodological conceptualization of the comparative study of religion.

In this article, I treat these two works as bookends and examine how the comparison of religion has taken place between their respec-

${ }^{1}$ I would like to thank Rachel McDermott and Kimberley Patton for their constructive comments on earlier drafts of this article. 
tive dates of publication. I offer a typology of methodological approaches used to construct and interpret comparisons of phenomena found in distinct religious traditions, and I assess the value of these methodologies on the basis of their consideration of similarities and differences, attentiveness to context, and effectiveness at illuminating the subject matter under consideration. ${ }^{2}$ By examining the strengths and weaknesses of comparative religion as it was practiced from 1982 to 2000 in light of Jonathan Z. Smith's critiques, I hope to provide a sense of the directions in which the scholarly comparison of religion ought to proceed in the twenty-first century.

The sources cited in this study have been selected out of a large, eclectic corpus of scholarly works engaged in the comparison of religion which were published during the time period under consideration. I define the comparison of religion as the examination, in a unified work, of sources from at least two distinct religious traditions addressing an aspect of religion common to the comparands. Of the dozens of publications meeting these criteria which I have examined, I refer here only to those that exemplify clearly a particular approach to the comparison of religions, although these are certainly not the only or even the best-known works that make use of their respective methodologies. ${ }^{3}$ Smith (1982a: 22-24, 1990: 47-51) and other scholars in this period also classified or described several approaches to comparative religion, but I found that no existing typology adequately accounts for the full range of methods used in comparative scholarship published between 1982 and 2000. For this reason, I have selectively drawn from earlier classificatory systems and their terminology in the creation of my own typology of approaches to the comparison of religion. ${ }^{4}$ I have divided these approaches into the broad categories of "comparative focus on similarity", "comparative focus on difference", "comparative focus on genus-species relationship", and "the use of comparison to refocus".

${ }^{2}$ Due to constraints of space, this work will not examine the ways in which comparativists have responded to the postmodernist critique that scholarly biases irreparably mar all comparisons of religion.

${ }^{3}$ Beyond selecting works on the basis of their utility as methodological exemplars, I must acknowledge that these works also tend to focus on areas related to my own personal interest and scholarly expertise. The approaches to comparative religion which they exemplify, however, are found in works covering a much wider array of subjects.

${ }_{4}$ The works that influenced my system of classifying and defining approaches to the comparison of religion include Carman 1994: 36-37; Doniger 1998; Holdrege 1996: 2-3, 19-25; White (2000: 50-51). 


\section{It's all the same to me}

One of the common functions of the comparison of religion in the "bad old days" rejected by postmodern critics of the field is to identify similarities between aspects of different religions for the purpose of showing that the two religions are similar if not identical with regard to the aspect under consideration. Jonathan Z. Smith (1982a) asserts that this approach to comparative religion tends to be ahistorical and offers no objective definition of what constitutes similarity. He, along with many critics of the comparative enterprise, favors an approach focusing on differences between religions. Nevertheless, the practice of emphasizing - and overemphasizing - the similarities among religions continues in various forms, some of which can in fact produce valuable insights regarding the traditions being examined.

In many cases, comparativists content themselves with the mere presentation of similarities. Emile Sahliyeh's essay, "Religious fundamentalisms compared" (1995), on Palestinian Islamists, militant Lebanese Shi'ites, and radical Sikhs provides a simple example of this simple form of comparison. Sahliyeh "compares the three religious movements in terms of the explanatory variables that account for their emergence and compares their structures, ideologies, and relationships with the existing power holders ... to point out the common causes and the properties of fundamentalism in the three communities" (1995: 136). For Sahliyeh, to "compare" means to "point out common causes and ... properties". The essay itself does little more than identify shared attributes of each community under examination: in each case, fundamentalism rose in a political climate characterized by a relative degree of democratization, each movement possesses a strong sense of "ethnonationalism" and a millenarian world view, each is marked by a propensity toward violence and a selective attitude toward modernization, and so on. It is unclear what the significance is of these similarities; in this model of comparison, it is enough simply to demonstrate their existence. Whatever differences may exist between the movements can be dismissed in an introductory sentence: "Despite their differences, the three fundamentalism movements share a number of features."

A more extreme form of this exclusive focus on similarity is an assertion of identity, in which the comparativist effectively maintains that there are no significant differences between two religious traditions with regard to a given subject. This thoroughly discredited 
methodological approach to comparative religion has become hard to find, but has not yet disappeared from the discipline; see, for example, Judith Romney Wegner's article, "Islamic and talmudic jurisprudence" (1982), which presents the former as being little more than the latter in Arabic. Yet the problem inherent in the assertion of identity - the fact that this approach portrays elements of distinct religions as being the same, in the process ignoring very real differences in the content and context of the phenomena being examined-also exists in the less extreme presentation of similarity model, which Smith and others criticize for this reason.

These same scholars also single out for critique a related approach to the comparison of distinct religious traditions that explains similarity as the reflection of an historical relationship between them. This approach to comparison, as many of its detractors have contended, does indeed lend itself to assertions of the superiority of one tradition over another; Romney Wegner, for example, posits "borrowing" of talmudic concepts to deny the existence of anything authentically Islamic about Islamic jurisprudence (1982: 26, 66). Nevertheless, the comparison of religion can be used credibly to demonstrate the existence of "borrowing" across religious lines. Sarah Kamin, for example, argues persuasively in her article, "Affinities between Jewish and Christian exegesis" (1991), that the interpretive approach to scripture used by the twelfth-century Rabbi Samuel b. Meir (known by the acronym "Rashbam") was shaped by Christian approaches to biblical interpretation. Kamin builds her case by demonstrating that Rashbam's exegetical method differs from that found in earlier rabbinic sources yet is strikingly similar to the Christian dichotomy of "literal" and "spiritual" senses of scripture exemplified at the time in the work of Hugh of St. Victor and rooted in early Christian biblical interpretation. Since Northern European rabbis such as Rashbam could not have learned the concept of two senses of scripture from Jewish sources, Kamin asserts that rabbinic appeal to a "literal" sense in the Middle Ages must derive from an historical relationship with the longstanding Christian use of this approach to biblical interpretation. Kamin's identification of similar phenomena in two distinct religions, an inherently comparative endeavor, yields new insights into the historical relationship of these phenomena.

Not all similarities are due to common origins, however. As Michael Cook points out in his book, Commanding Right and Forbidding Wrong in Islamic Thought (2000), although notions similar to this Is- 
lamic concept exist in Judaism and Christianity there is no clear indication of an historical relationship between them. Cook offers the valuable cautionary conclusion that "while we should not rule out a monogenetic view of the incidence of the scholastic doctrines we have reviewed, the fact is that we have little chance of establishing such a hypothesis" (2000: 579). It is also important to recognize that history is not destiny, nor is it necessarily the most important explanation of similarities. Wendy Doniger (1998: 139-142) notes that in the numerous cases in which the "same myth" appears in multiple cultures, the fact of historical affinity does not provide an explanation for the existence of the myth in its various forms and contexts. Whatever the historical relationship between similar elements of distinct traditions, their differences frequently extend beyond the vagaries of imprecise borrowing and are significant in their own right. Furthermore, the mere existence of an historical relationship between concepts found in two traditions does not account for why the concept developed roots in multiple distinct religious contexts. Kamin's comparison of medieval Jewish and Christian interpretation effectively illuminates the history behind Rashbam's attention to the "literal sense" of scripture, but her methodology would be unsuitable for the consideration of such questions as why this approach to scripture was attractive to medieval rabbis or how Rashbam shaped this approach to meet his own needs.

The appeal to an historical relationship between comparands on the basis of their shared characteristics is only one approach to the explanation of similarity, a scholarly effort to go beyond the cataloging of parallels found in the "presentation of similarity" model and to analyze the results of the comparison. Another means of explanation is to posit that similarities are a reflection of a conceptual relationship between historically unrelated comparands. Cook, for example, raises the possibility that the principle of commanding right and forbidding wrong might be a natural outgrowth of monotheism (Cook 2000: 579-582). ${ }^{5}$ The cautionary remarks of Cook and Doniger about pos-

${ }^{5}$ One can also explain the similarity of comparands as being a reflection of parallel historical contexts. I did not find any use of this explanatory model in the literature I surveyed. To cite an example from my own research, one can argue that the rise in religious restrictions regarding eating the food of members of another religion found in early medieval Christianity and modern Islam correlates with the fact that at these particular historical moments these communities consider(ed) themselves to be at risk of assimilation. 
iting an historical relationship apply to other efforts to explain similarity as well: it is difficult to demonstrate conclusively that the similarities result from the specific explanation being offered, and that explanation does not on its own account for the particular details of how the shared phenomenon functions in each religious tradition.

\section{The difference a difference makes}

Wendy Doniger is among the contemporary scholars of comparative religion who, in light of the postmodernist critique, devote considerable attention to the differences between comparands, what Doniger calls "the dog that doesn't bark". "Comparison makes it possible for us literally to cross-examine cultures, by using a myth from one culture to reveal to us what is not telling from another culture" (Doniger 1998: 33, emphases original). Yet Doniger argues forcefully that even in scholarship oriented toward identifying differences between religious traditions and discovering what is unique about each, one cannot neglect to find points of similarity; to insist that difference is absolute, Doniger asserts, is to render the "other" unintelligible and perhaps non-human (Doniger 2000: 64-66). In contrast to comparative works focusing on similarity, in which difference is ignored, comparative works focusing on difference all pay at least some attention to similarity, whether out of sentiments like those expressed by Doniger or simply out of the need to justify the merit of the comparative exercise.

Focus on the differences between comparands can take several forms. The most basic approach, methodologically, is a presentation of differences without analysis or opinion. Frequently, this model of comparison is used in works that seek to promote or inform inter-religious dialogue; in this context, emphasis of similarity has an additional purpose. "To carry on a conversation across different cultural traditions it is necessary to find ideas, concerns, and other points of commonality close enough and substantial enough to support the building of bridges of mutual understanding between them" (Johnson 1997: 169). Even so, the goal of the conversation is to understand something that is, in fact, different. The participants in the conversation, and the scholar attempting to facilitate it, acknowledge this difference by recognizing that "bridges of mutual understanding" must be built over a chasm of mutual unintelligibility. 
This approach to comparative religion can be seen in a book by Leo D. Lefebure, The Buddha and the Christ (1993), which explains Mahayana Buddhism to a Western Christian audience and identifies the similarities and differences between these traditions. So, for example, Lefebure maintains that both traditions associate salvific power with one bearer of good news able to redeem humankind and the entire cosmos; "the similarities in the descriptions of the cosmic dimensions of the Buddha and the Christ do not, however, dissolve the real differences between the two traditions", which Lefebure proceeds to enumerate in detail (1993: 55-56). The author does not attempt to explain why these religions have different theologies, nor does he offer an evaluation of these differences. Rather, he simply notes the similarities and differences and clarifies to an extent their implications, leaving the rest up to his readers. In this respect, this model of comparison shares a methodological shortcoming with the presentation of similarities model discussed previously: both constitute little more than catalogs of information about their comparands. As neither of these approaches to the comparison of religion actually attempts to understand the significance of the data gathered through the act of comparison, they produce conclusions which one could reach through the study of each religious tradition independently. Comparison without analysis does little to advance the academic study of religion.

Not all analysis of differences between religious traditions, however, befits the goals of the academy. Jonathan Z. Smith, in Drudgery Divine (1990), is neither the first nor the last to point out the fact that older studies of comparative religion - and many recent ones - are either implicitly or explicitly designed to demonstrate the superiority of Protestant Christianity. Protestants, however, by no means have a monopoly on such evaluations of difference, nor do scholars who employ this methodology always favor their own tradition. In "Islamic law and Jewish law on deserted wives/missing husbands" (2000), Vardit Rispler-Chaim attempts "to assess whether the status of the Jewish woman is indeed inferior when compared to the status of the Muslim woman according to their respective law systems" (2000: 257); she concludes that Islamic law is superior. Comparisons can also be made against abstract notions of what is "good" or "useful". This can be seen in Robert Cummings Neville's Behind the Masks of God (1991), which includes a comparison of Confucian and Christian notions regarding individuation, the development of personal relations with 
particular circumstances in life. "The purpose here is more practical than historical in that it hopes to mine both traditions for useful structures for understanding our own life and times" (1991: 127). This sort of evaluation, although perfectly appropriate in the realm of theology or women's advocacy and commonplace among religious practitioners, is not in keeping with the professional obligation of academic scholars of religion to strive for objectivity in their research.

Mark Cohen's Under Crescent and Cross (1994), in contrast, is a comparative work that does strive for objectivity in its explanation of how and why Islamic-Jewish and Christian-Jewish relations followed different courses in the Middle Ages. Cohen notes, for example, that Muslims referred to Jewish law using neutral if not positive language while Christians used comparable terms disparagingly. He explains this difference in light of the historical relationship these religions had with Judaism and the threat of "Judaizing" each perceived in its own ranks (1994: 27-28). Cohen's explanation of difference as a reflection of non-parallel historical contexts is one approach to the explanation of difference. One could also posit, for example, that difference is a reflection of the lack of a conceptual relationship between the religious traditions being compared, as Michael Cook suggests in noting that non-monotheistic Eastern religions do not articulate the concept of commanding right and forbidding wrong found in Islam as well as Judaism and Christianity (Cook 2000: 580). The value of these methods of explaining differences identified through comparative analysis can be seen not only in their ability to identify aspects of a particular tradition as being distinctive (a benefit of the presentation of difference model as well) but also in their ability to account for the distinctiveness of these aspects through consideration of the specific contexts in which the comparands appear. Cook's caution about the difficulty of proving the relationship between these differences and a specific factor deserves to be reiterated, but Doniger's remarks on the limitations of explanations of similarity - that they do not account for difference or context - do not apply to comparisons of religion that explain difference.

\section{All in the family}

Thus far, we have considered methods of comparative religion focusing primarily on either that which is shared between the comparands 
or that which is distinctive. A third methodological category contains approaches which are more complex in their consideration of similarity and difference. Some comparative works explore the relationship of a general aspect of religion with the similar yet distinct specific manifestations of that aspect in the religious traditions under examination. This type of comparison is analogous to scientific taxonomy of individual species into larger units such as genus, family, and class. In both cases, one can only examine evidence derived from observation at the species level; the larger classifications are nothing more than useful abstractions indicating shared characteristics. In the case of biological taxonomy, these similarities are understood to indicate shared historical origins. This is not necessarily the case in comparisons of religion that consider the "genus" to which individual "species" belong, as the genus is frequently defined on the basis of a conceptual rather than an historical relationship. A clearer understanding of the genus not only enhances our understanding of common themes found in multiple religions but also enables scholars to apply these generic characteristics to specific examples of their application, thus gaining a better understanding of particular religious traditions as well. One can also appeal to a religious genus to identify the elements of individual traditions, those not shared by other members of the genus, that make each species unique.

The focus on genus as a methodological approach to the study of religion is not necessarily comparative. Mark Juergensmeyer, in The New Cold War? (1993), a book on contemporary religious nationalism, only examines this subject as a general phenomenon and does not consider the individual movements he discusses as distinct entities. This may be contrasted with Sahliyeh's (1995) work on the same subject. Even though Juergensmeyer and Sahliyeh both examine the same religious movements and both emphasize their similarities, Sahliyeh focuses on the specific examples under consideration and not on the phenomenon as a whole. Sahliyeh studies individual trees; Juergensmeyer addresses the characteristics of the forest. The former does not examine the relationship of species to their shared genus, while the latter does not compare individual species in its discussion of that genus.

One can, however, compare trees to make an argument about the forest; that is, the comparison of a particular aspect of multiple distinct religions can be used to define the general characteristics of that aspect. A good example of this approach to examining a genus can 
be found in Bruce Lincoln's Discourse and the Construction of Society (1989), which offers the comparison, among others, of the function of Persian and English myths about whether mountains will be leveled in the end of days to create a flat earth. Lincoln argues that the proponents of flat-earth myths in both cultures were advocates of social egalitarianism while those who supported the preservation of social hierarchy produced myths extolling the eternal value of mountains (1989: 38-50). This comparison is not meant to demonstrate any specific cultural or contextual similarities between ancient Persia and seventeenth-century England, but rather to show how myths in general have been used throughout the world and throughout history to promote conceptions and constructions of society.

Lincoln's focus on the genus "myth" considers only the shared aspects of the specific myths he examines. Yet this approach to the comparison of religion can accommodate the consideration of both similarities and differences among the comparands. In What is Scripture? (1993), Wilfred Cantwell Smith attacks the prevailing definition of the genus "scripture" by emphasizing the differences between the Christian conception of the Bible commonly used to define the genus and the conception of scripture found in numerous non-Christian traditions. For example, Smith maintains that "Torah" in Judaism means simultaneously much more and much less than "Bible" as understood by Christians and that Buddhist scriptures contradict the Christian notion of a closed scriptural canon (1993: 92-123, 146175). Through focusing on the differences between the various species that make up the genus called "scripture", Smith mounts a compelling argument that the dominant understanding of the genus is inappropriate. Consideration of difference alone, however, is insufficient to define the genus more effectively. For this reason, Smith appeals to similarities in the role scripture plays in various religious traditions to redefine the genus "scripture" in terms of the relationship a community has with a text (1993: 18). An important methodological similarity of the genus-based arguments made by both Lincoln and Smith is that, while rooted in specific examples, they are intended to shed light on an entire class of phenomena, including species that are not examined in these works.

One further example of a comparative work that focuses on a religious genus is in order because of the added layer of complexity it contains. Barbara Holdrege, also writing on the subject of scripture in Veda and Torah (1996), analyzes and compares the role of these 
sacred texts in their respective traditions. Her argument, however, extends beyond the particulars of these two scriptures. Holdrege maintains that, despite the lack of an historical relationship between these traditions, Hinduism and Judaism share common characteristics - such as a focus on practice, observance, and ethnic identitynot found in belief-oriented and missionary religions like Christianity. Holdrege asserts 'that brahmanical 'Hinduism' and rabbinic 'Judaism' represent two species of the same genus and provide a model of 'religious traditions' that is distinctly different from the prevailing Christian-based model" (1996: 2-3). Holdrege thus sets up a three-tiered classificatory system: Hinduism and Judaism are distinct species in the genus "orthopractical, ethnic religions" (which Holdrege labels "embodied communities"); this genus, along with the genus "orthodox, missionary religions" containing Buddhism, Christianity, and Islam, are both members of the broader family of "religious traditions". This scheme enables Holdrege to offer a generic definition of scripture that applies to Hinduism and Judaism but not to Buddhism, Christianity, or Islam (1996: 413). While "scripture" is a common feature of all members of the family "religious traditions", Holdrege maintains, its function differs by genus. Methodologically, Holdrege's focus on genus is able to emphasize both similarity (between Hinduism and Judaism) and difference (between these religions and Christianity, etc.) in its definition of the nature of that genus, and, as a result, this methodology produces a more nuanced conclusion than the simpler focus on genus used by Lincoln and W. C. Smith.

The key to a comparative focus on genus is the construction "from the bottom up" of a genus on the basis of similarities among constituent species or, conversely, the limitation or destruction of that genus on the basis of differences among these species. One can, however, reverse the species-genus study and use a given definition of a genus to understand one or more of its species. This "top-down" focus on species is comparative when multiple species of the same genus are contrasted to identify what makes them distinct; this methodology thus relies heavily on the presentation of difference, much as the focus on genus often relies on a presentation of similarity. An example of such a focus on species is Christel Manning's sociological study of the attitudes of religious conservative women regarding feminism, God Gave Us the Right (1999). Manning interviewed women from comparable Orthodox Jewish, conservative Catholic, and evangelical 
Protestant communities to understand why they hold different attitudes regarding the proper roles of women and selected social issues. She concludes that these differences in opinion stem from the distinct beliefs, practices, cultures, and histories of each religious tradition. The differences among species (Jewish, Catholic, Protestant) account for why members of the same genus (religious conservative women) are distinct with regard to the aspect under examination (attitudes toward feminist issues). What distinguishes Manning's work methodologically from Mark Cohen's "explanation of difference" model is that Manning consciously and carefully establishes a general framework in which to contrast her otherwise similar subjects; Cohen takes the generic similarity of his comparands for granted and does not engage his subject matter at the generic level.

\section{Now, for a different point of view}

An implied but crucial aspect of all of the models examined so far is that the comparison of religion - whether focused on similarity, difference, or both - produces the data of interest to the scholar. The purpose of "presentation" models is to catalog similarities or differences through the process of comparison, while the objective of the more complicated methodologies is to identify the significance of or draw conclusions from the results of the comparison. The fact that two religions are similar with respect to a particular aspect is what prompts arguments for historical or conceptual relationship or that demonstrates the existence of a genus; the fact that they are different prompts the articulation of species-specific distinctiveness and provides the grist for examination or evaluation. There is, however, another approach to the comparison of religion, one in which the scholarly "action" takes place outside of the inter-religious space of comparison and is embedded firmly in one religious tradition or another. In this model, comparison functions as a lens. Much as a microscope offers new insights even into specimens that can be seen with the naked eye, the religious tradition being brought for the purpose of comparison serves to provide a new perspective on the tradition being examined, to raise new questions or offer new possible ways of understanding the target tradition. The dissection of the tradition in the Petri dish, however, is not performed by means of the lens, but rather by the scalpel which the scientist, looking through the 
comparative lens, uses to operate on the tradition directly, in its own context.

At its root, this methodology is quite straight-forward: it relies on comparison for the generation of hypotheses. In the words of Bernard Jackson, "it is indeed the function of the comparative approach to ask questions and suggest hypotheses; answers and proof can only be provided by internal evidence" (Jackson 1994: 181). I would dispute Jackson's assertion that comparison can never provide answers and proofs (in fact, Jackson's own essay, "From dharma to law", is a good example of the use of comparison to better understand the genus "religious law"), but he does articulate effectively the fact that the most profitable comparisons are often those that raise questions rather than those that attempt to answer them. The lens model of comparison can serve this function quite well, but it has also been used for more ambitious purposes.

We have already encountered Wendy Doniger's use of comparison to identify dogs that "don't bark", that is, to identify an absence of a particular element in one myth by noting the presence of that element in other myths on the same subject. Comparison yields the question, why is this element absent from this myth? It can also provide potential answers to that question by applying ideas from one myth to another. To take an example from Doniger's The Implied Spider (1998), by reading the biblical story of Judah and Tamar in light of related stories such as the tale of Martin Guerre, one recognizes more clearly the dilemma of how Judah could have failed to recognize Tamar even after sleeping with her. Doniger goes a step further and suggests that, in addition to reading traditional commentary on the biblical passage in search of solutions to this dilemma, a biblical scholar ought to read the passage through the lens of the "unofficial commentary" provided by other myths in order "to discipline his or her own imagination of what might have been in the minds of Judah and Tamar" (1998: 39). This use of comparison to learn from parallel cases, Doniger acknowledges, has its limitations; although it is interesting to hypothesize that Judah, like the wife of Martin Guerre, was actually aware of the true identity of his sexual partner, there is no reason to assume that the biblical author had this in mind. Nevertheless, once one asserts the impossibility of understanding exactly what the author had in mind, the interpretations suggested in other myths are no less valuable than one's own interpretations, and sometimes are even more valuable. 
The limitations of what one can learn from parallel cases are clearly seen in Reuven Firestone's "Comparative studies in Bible and Qur'ân" (2000), a somewhat tongue-in-cheek essay reading the biblical account of Abraham's near-sacrifice of Isaac in light of the parallel quranic account, a pointed inversion of the Orientalist project of interpreting the Quran in light of the Bible. Firestone offers several arguments to support the plausibility of reading the quranic account - in which the victim is not named and, perhaps, actually slaughtered - as a preservation of a pre-biblical layer of the sacrifice tradition, and he provides an intriguing suggestion of how such a narrative would fit into the larger chronology of the biblical Abraham story cycle. Nevertheless, Firestone acknowledges the impossibility of being able to support this hypothesis conclusively without using the tools of biblical history, either the archeological discovery of an ancient text or critical analysis of the text of the Bible itself. When arguing about "empirical" matters of history or authorial intent, the lens model of comparison can only offer questions or suggest possibilities, which must then be explored in the context of the tradition under examination. In more conceptual or "imaginative" areas, however, one can apply the lessons learned from parallels more directly.

It is interesting that Jonathan Z. Smith himself, whose critique of comparisons of religion has sparked so much methodological reflection on the subject, utilizes this "imaginative" approach to learning from parallel cases in "The devil in Mr. Jones" (1982b), an essay on the mass suicide at Jonestown. Smith asserts that scholars of religion must be able to explain this religious phenomenon, to remove its uniqueness by reducing it to a known category of religious behavior (1982b: 111-112). Smith performs this act of reduction through a comparison which Malcolm David Eckel calls "imaginative and ironical juxtaposition" (Eckel 2000: 56), one in which Euripides' The Bacchae becomes a lens for understanding why the residents of Jonestown were willing to commit mass suicide. While acknowledging the existence of profound differences between Euripides' characters and Jones' followers, Smith emphasizes similarities such as the fact that both groups attempted to overcome distinctions, inhabited subversive space, functioned as entities independent of society at large, and felt an immanent sense of outside invasion.

How is Smith's comparison different from Sahliyeh's presentation of similarities, the model with which we began and which Smith himself criticizes for its failure to emphasize difference? On one level, 
there is no distinction: both works pay lip service to the existence of difference but emphasize those features which are shared. On another level, however, the difference is quite substantial as these authors make different arguments on the basis of the similarity which they have identified. Smith's interest is not simply to point out the similarities between Jonestown and The Bacchae, but rather to use The Bacchae to understand Jonestown, to render the mass suicide intelligible. The key to the distinction, as Eckel points out, is the "imaginative" function of the comparison: Smith is not so much arguing for the existence of "real" similarity (that the events at Jonestown are ontologically similar to, identical to, derived from, or in the same genus as the conclusion of Euripides' play) as he is arguing that it is useful for the scholar to imagine that they are similar. This imagined similarity, regardless of the reality behind it, enables the scholar to comprehend what would otherwise be incomprehensible, and thereby enables scholarly analysis of Jonestown to occur. The analysis itself, however, remains entirely focused on Jonestown; Smith's comparison functions as a scholarly lens, not an end unto itself.

\section{The contextual conundrum}

A crucial issue facing scholars who engage in the comparison of religions, regardless of their methodological approaches, is the determination of how much context to consider. The comparison of religious texts or phenomena independently of their historical and cultural contexts results in conclusions possessing dubious value, drawing, justifiably, the critiques of both Jonathan Z. Smith and postmodernists who generally emphasize the overarching importance of difference. The challenge posed by context to the comparison of religion, however, is complicated by the fact that the more context one considers the less similar the comparands become, yet all meaningful study of multiple religious traditions must be based on at least a certain degree of similarity between the traditions being examined.

One method of handling context is to attempt to compare only subjects that share the same context. Mark Juergensmeyer, for example, only considers in his work on religious nationalism movements that meet his pre-determined definition for that generic category. "I have chosen movements that share these characteristics: they reject secular nationalism, they regard secular nationalism as Western and 
neocolonial; their rejection is fundamental - often hostile and violent; they wage their struggle with religious rhetoric, ideology, and leadership; and they offer a religious alternative to the secular nation-state" (Juergensmeyer 1993: 46). Emile Sahliyeh and others whose comparisons are solely designed to present similarities evidently employ similar selection screens in determining the focus of their research. Of course, there are contextual differences between the Palestinian, Lebanese, and Sikh movements that Sahliyeh discusses, not to mention the Ukranian, Sri Lankan, Israeli, and Mongolian movements that Juergensmeyer considers. Those who study any of these specific movements will quickly recognize the limitations of noncontextualized general conclusions.

Christel Manning, in her sociological study of religious conservative women, focuses on the differences between species rather than on their similarities or generic characteristics. She too attempted to select subject communities similar to one another with regard to extraneous factors such as regional culture and socio-economic status so as to avoid difficulties regarding context, yet her efforts in this regard were only partially successful. Orthodox Jewish women in Manning's study, for example, differed from evangelical Protestant women not only in the traditional structures of their religious communities but also in the level of secular education they received. Manning ascribes the tendency among her Orthodox subjects to be stronger supporters of equality in the workplace than their evangelical counterparts to their higher levels of education, while accounting for the greater Orthodox support for increased roles for women in religious leadership on the basis of the different traditional structures within Jewish and Christian communities (Manning 1999: 103, 12223). One can make an equally strong argument, however, for reversing Manning's conclusions, explaining differing attitudes toward workplace issues on the basis of differing traditional roles for women and pointing to differences in secular education to account for different attitudes toward women in religious leadership positions. Even after constructing a comparison based on fairly similar communities, there remain too many differences between the comparands to be able to determine conclusively which attitudes stem from which factors. Efforts to control for context in the process of selecting comparands seem fated to be only partially successful, and such efforts inherently limit the range of comparisons that can be made.

An alternate approach to selecting contextually similar subjects for 
comparison is to compare elements from multiple religious traditions only after examining them in their original contexts. Barbara Holdrege, in her work on Veda and Torah, makes a point of adopting this methodology in response to Smith's critiques that comparative religion pays insufficient attention to differences, to the diachronic dimension of religious phenomena, and to cultural context. Holdrege addresses these concerns by employing a three-phase approach to comparison: a tradition-specific analysis of the function of each scripture in its own context, followed by comparative analysis highlighting both similarities and differences, and finally an examination of the significance of the similarities and differences in light of the religio-cultural contexts of each scripture (Holdrege 1996: 20-25). One outcome of this thorough approach to the comparison of religion is that Holdrege effectively sandwiches two-and-a-half books - one on Veda, one on Torah, plus comparative analyses - inside a single dust jacket. Mark Cohen adopts a similar approach in his comparison of medieval Christian and Muslim attitudes toward Judaism (Cohen 1994), although his "two-and-a-half books" are substantially shorter and written without the same methodological self-awareness. For scholars who are able and willing to put in the effort, this approach to the comparison of religion does succeed in addressing the concerns regarding context and overemphasis of similarity raised by Smith and other critics.

A more radical response to the challenge of adequately addressing contextual issues in the process of comparison is to redefine the context of the comparands entirely. Wendy Doniger acknowledges that much is lost when context is not considered in the process of comparing elements from multiple traditions, and insists that comparativists must themselves be able to understand their subject matter in its original contexts. Nevertheless, she ascribes great value to what can be gained through comparison: a recontextualization of the phenomena under examination in light of one another (Doniger 1998: 45). Doniger accomplishes this recontexualization by setting aside the original, cultural context of a myth, instead focusing on its "universal" context (i.e., its relationship to similar myths from other cultures) and its individuality as a unique product of a particular author. "What do we lose by this emphasis on the individual text? We lose the sort of big picture that is suggested by statistical analyses, a rough tabulation that is useful for cultural studies ... Yet we do get a big picture, of a different sort, by putting all the individual texts to- 
gether" (Doniger 1998: 74). What we do not get is a comparison that enriches our understanding of the individual text as situated in its cultural and historical context. Recontextualization offers a powerful way to utilize the full potential of comparison, but it is only suitable for certain types of scholarship.

\section{Methodological directions in the comparison of religion}

A graphic representation of the methods of comparative religion discussed above provides an effective means of summarizing the relationships between them, along with the strengths and weaknesses of each. The chart that follows sorts these approaches to the comparison of religion by category.

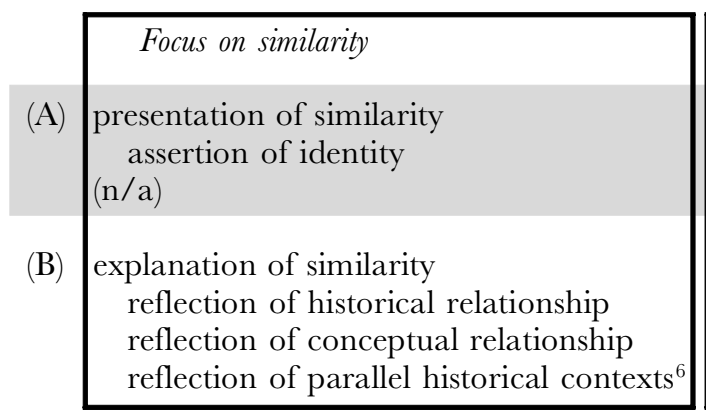

Focus on difference

presentation of difference

(n/a)

evaluation of difference

explanation of difference

$(\mathrm{n} / \mathrm{a})$

reflection of lack of conceptual relationship reflection of non-parallel historical contexts

(G)

(D)

$$
\begin{aligned}
& \text { Focus on genus-species relationship } \\
& \text { focus on genus } \\
& \text { focus on species }
\end{aligned}
$$

Use of comparison to refocus

generation of hypotheses

learning from parallels

${ }^{6}$ This model of comparison is unattested in the literature published between 1982 and 2000 which I examined; see note 5 above. 
This chart can be read in multiple ways. Scanned horizontally, it illustrates the respective emphases on similarity, difference, or both found in each of these models of comparison. It also identifies the relationship between those models that focus on similarity and on difference. One can present one's comparative findings without analysis regardless of one's choice of emphasis, and many of the explanations that one can offer for similarity or difference reflect two sides of the same coins: historical analysis, conceptual analysis, and contextual analysis. Not all approaches, however, can be used to account for both similarity and difference, which is why there are gaps in these lists.

This survey of methodological approaches to the comparison of religion, however, demonstrates that the focus on similarity or difference is not the most significant factor in determining the suitability of any given comparative model; valuable comparisons as well as specious ones can fall into any of the broad categories in the above typology. For this reason, I have also arranged this chart to be read vertically, grouping together comparative methods by their function and suitability for academic scholarship.

The top portion of the chart, labeled (A), contains methodological approaches to comparative religion that ought not be used in scholarship. The assertion of identity is both factually impossible and inappropriate methodologically in the post-colonialist academy. The evaluation of difference is inherently subjective and ought properly to remain in the realm of the religious practitioner. Presentation of similarity or of difference is not in and of itself objectionable - although the former may be criticized for its over-simplification-but should be abandoned nevertheless on account of its lack of utility: a mere collection of observations does not constitute a work of scholarship. Although these approaches all have a long and "distinguished" (for better and for worse) history in the field of religious studies, they ought to have been retired long since.

Skipping down the chart, the use of comparison to generate hypotheses $(\mathrm{C})$ is suitable for all types of scholarly inquiry. Comparison of religions offers a valuable means of bringing into question deeply rooted assumptions regarding what is "normative" in any given tradition as well as offering possible explanations for problems encountered in the study of a single tradition. In this approach, comparison becomes one of the tools used in the "brainstorming" stage of research. As comparison does not play any role in the evaluation of the 
questions or hypotheses it raises, no sophisticated comparative methodology is needed; the scholar returns to the analytical tools used in her or his own field to consider the possibilities raised elsewhere.

The remaining approaches to the comparison of religion are all appropriate and valuable for academic scholarship, but are limited in their suitability for particular research projects. Models in section (B) - the various means of explaining similarity or difference and the studies of genus-species relationship - are best used in the context of "empirical" research. These approaches to comparison, when used properly, can produce information about actual historical or conceptual relationships between phenomena found in distinct religious traditions: why the author of a particular myth constructed it as he or she did, why religions share a particular concept or differ in their attitudes toward a given subject, and so on. A drawback to this approach, however, is the difficulty inherent in proving an empirical argument. The explanation models of comparison are also limited by their focus on either similarity or difference; explanations of difference fail to account for the root similarity of the comparands, while explanations of similarity are of no use in accounting for the differences between them. The explanation of similarity on the basis of historical relationship is further limited in that it cannot account for why such a relationship developed at all. Despite these limitations, however, empirical approaches to the comparison of religion can be constructed so as to avoid the overemphasis of similarity and neglect of context for which the comparative enterprise has been criticized. The most suitable method for handling context in these models is to examine the comparands contextually prior to comparing them; although substantially more demanding than a context-sensitive selection of comparands, this approach yields more nuanced and defensible conclusions.

While most of the approaches to comparison found in works from 1982-2000 are best suited for empirical studies, the "learning from parallels" model (D) is particularly appropriate for "imaginative" studies of religion. Because of the recontextualization inherently associated with this methodology, it cannot be used to understand religious phenomena in their original contexts. Yet this limitation also constitutes the greatest strength of this use of comparison as a lens: recontextualization facilitates entirely new ways to understand a given subject. This approach enables scholars to make the unintelligible meaningful and to discover new meaning in well-known elements 
of a religious tradition. This comparative methodology can be employed creatively in studies of particular aspects of individual religions or in sweeping surveys of broader religious motifs.

In sum, the methodology of comparative religion has improved substantially since Jonathan Z. Smith critiqued it in "In Comparison a Magic Dwells" just over twenty years ago. The field is far from perfect, and numerous works have been published since 1982 that continue to make use of problematic or discredited approaches to comparison. Yet in the past two decades scholars have developed more nuanced and sophisticated comparative models that effectively take into account the postmodernist emphasis on difference and context. The scholarly value of many of their works constitutes at least as strong a rationale for continuing the responsible comparative study of religion as the arguments presented in A Magic Still Dwells.

Department of Religion

Columbia University

617 Kent Hall, MC 3949

1140 Amsterdam Avenue

New York, NY 10027

USA

\section{References}

Carman, J. B. (1994). Majesty and Meekness: A Comparative Study of Contrast and Harmony in the Concept of God. Grand Rapids, MI: William B. Eerdmans.

Cohen, M. R. (1994). Under Crescent and Cross: The Jews in the Middle Ages. Princeton: Princeton University Press.

Cook, M. (2000). Commanding Right and Forbidding Wrong in Islamic Thought. Princeton: Princeton University Press.

Doniger, W. (1998). The Implied Spider: Politics and Theology in Myth. New York: Columbia University Press.

- (2000). Post-modern and -colonial -structural comparisons. In K. C. Patton and B. C. Ray (eds), A Magic Still Dwells: Comparative Religion in the Postmodern Age, 6374. Berkeley: University of California Press.

Eckel, M. D. (2000). Contested identities: The study of Buddhism in the postmodern world. In K. C. Patton and B. C. Ray (eds), A Magic Still Dwells: Comparative Religion in the Postmodern Age, 55-62. Berkeley: University of California Press.

Firestone, R. (2000). Comparative studies in Bible and Qur'ân: A fresh look at Genesis 22 in light of Sura 37. In B. H. Hary, J. J. Hayes, and F. Astren (eds), fudaism and Islam: Boundaries, Communication and Interaction: Essays in Honor of William M. Brinner, 169-184. Leiden: Brill.

Holdrege, B. A. (1996). Veda and Torah: Transcending the Textuality of Scripture. Albany: State University of New York Press. 
Jackson, B. S. (1994). From dharma to law. In H. Goodman (ed.), Between Ferusalem and Benares: Comparative Studies in Judaism and Hinduism, 181-193. Albany: State University of New York Press.

Johnson, J. T. (1997). The Holy War Idea in Western and Islamic Traditions. University Park: Pennsylvania State University Press.

Juergensmeyer, M. (1993). The New Cold War? Religious Nationalism Confronts the Secular State. Berkeley: University of California Press.

Kamin, S. (1991). Affinities between Jewish and Christian exegesis in 12th-century northern France. In Fews and Christians Interpret the Bible. Jerusalem: Magnes.

Lefebure, L. D. (1993). The Buddha and the Christ: Explorations in Buddhist and Christian Dialogue. New York: Orbis.

Lincoln, B. (1989). Discourse and the Construction of Society: Comparative Studies of Myth, Ritual, and Classification. New York: Oxford University Press.

Manning, C. (1999). God Gave Us the Right: Conservative Catholic, Evangelical Protestant, and Orthodox Jewish Women Grapple with Feminism. New Brunswick, NJ: Rutgers University Press.

Neville, R. C. (1991). Behind the Masks of God: An Essay Toward Comparative Theology. Albany: State University of New York Press.

Patton, K. C. and B. C. Ray (eds) (2000). A Magic Still Dwells: Comparative Religion in the Postmodern Age. Berkeley: University of California Press.

Rispler-Chaim, V. (2000). Islamic law and Jewish law on deserted wives/missing husbands: Humanitarian considerations. In B. H. Hary, J. L. Hayes, and F. Astren (eds), Fudaism and Islam: Boundaries, Communication and Interaction: Essays in Honor of William M. Brinner, 257-268. Leiden: Brill.

Romney Wegner, J. (1982). Islamic and talmudic jurisprudence: The four roots of Islamic law and their talmudic counterparts. American Fournal of Legal History 26: 25-71.

Sahliyeh, E. (1995). Religious fundamentalisms compared: Palestinian Islamists, militant Lebanese Shi'ites, and radical Sikhs. In M. E. Marty and R. S. Appleby (eds), Fundamentalisms Comprehended, 135-152. Chicago: University of Chicago Press.

Smith, J. Z. (1982a). In comparison a magic dwells. In Imagining Religion: From Babylon to Fonestown, 19-35. Chicago: University of Chicago Press.

- (1982b). The devil in Mr. Jones. In Imagining Religion: From Babylon to Fonestown, 102-120. Chicago: University of Chicago Press.

- (1990). Drudgery Divine: On the Comparison of Early Christianities and the Religions of Late Antiquity. London: School of Oriental and African Studies; Chicago: University of Chicago Press.

Smith, W. C. (1993). What Is Scripture? A Comparative Approach. Minneapolis: Fortress.

White, D. G. (2000). The scholar as mythographer: Comparative Indo-European myth and postmodern concerns. In K. C. Patton and B. C. Ray (eds), A Magic Still Dwells: Comparative Religion in the Postmodern Age, 47-54. Berkeley: University of California Press. 
Copyright of Method \& Theory in the Study of Religion is the property of Brill Academic Publishers and its content may not be copied or emailed to multiple sites or posted to a listserv without the copyright holder's express written permission. However, users may print, download, or email articles for individual use. 